\title{
Long-term melatonin administration enhances the antioxidant potential of human plasma maintained after discontinuation of the treatment
}

\author{
Aleksandra Piechota ${ }^{1}$, Stanisława Lipińska ${ }^{2}$, Janusz Szemraj ${ }^{3}$ and Anna Gorąca ${ }^{1}$ \\ ${ }^{1}$ Chair of Experimental and Clinical Physiology Department of Cardiovascular Physiology, Medical University of Lodz, Lodz, \\ Poland \\ ${ }^{2}$ Chair of Experimental and Clinical Physiology Department of Clinical Physiology, Medical University of Lodz, Lodz, Poland \\ ${ }^{3}$ Department of Biochemistry, Medical University of Lodz, Lodz, Poland
}

\begin{abstract}
We investigated the effect of long-term oral melatonin administration on the antioxidant capacity of plasma. The study was performed on healthy volunteers divided into two groups: the control group (without melatonin treatment) and the study group treated with $6 \mathrm{mg}$ of melatonin per day for two weeks, 2 hours before bedtime. Blood samples were drawn: before melatonin administration, on the $7^{\text {th }}$ and $14^{\text {th }}$ day of melatonin treatment and on the $10^{\text {th }}$ day after the last dose of melatonin. It was shown that oral administration of melatonin increases plasma antioxidant ferric reducing ability (FRAP assay) ( $p<0.05)$ and DPPH (1,1-diphenyl-2-picrylhydrazyl) radical scavenging $(p<0.01)$, and decreases thiobarbituric acid reactive substances (TBARS) $(p<0.05)$ and DNA damage $(p<0.001)$. This protective effect is maintained for at last 10 days after discontinuation of the treatment.

The present work highlights that the antioxidant capacity of plasma was significantly higher on the $10^{\text {th }}$ day after the discontinuation of melatonin treatment than on the $14^{\text {th }}$ day of its administration. Our findings indicated that a long-term oral melatonin administration maintained the increased antioxidant capacity of plasma and prevented oxidative damage to DNA after hormone administration was discontinued.
\end{abstract}

Key words: Melatonin — Antioxidant activity — Oxidative stress — Free radical

Abbreviations: DPPH, 1,1-diphenyl-2-picrylhydrazyl; FRAP, ferric reducing ability of plasma; $\mathrm{H}_{2} \mathrm{O}_{2}$, hydrogen peroxide; MEL, melatonin; $\mathrm{OH}^{\bullet}$, hydrogen radical; ROS, reactive oxygen species; RNS, reactive nitrogen species; TBARS, thiobarbituric acid reactive substances.

\section{Introduction}

Reactive oxygen species (ROS) and reactive nitrogen species (RNS) are involved in the regulation of many vital bodily processes. ROS and RNS activate enzymes take part in phagocytosis, regulate vascular tone and play an important role in the host inflammatory response. However, high levels of ROS have been considered to be potentially damaging to cellular macromolecules and have been implicated in the

Correspondence to: Aleksandra Piechota, Experimental and Clinical Physiology, Department of Cardiovascular Physiology, Medical University, Mazowiecka 6/8, 92-215 Łódź, Poland

E-mail: piechota.aleksandra@wp.pl pathogenesis of various chronic diseases (Kawanishi et al. 2006). Critical sites of ROS attack are the cell membranes and membranes of intracellular organelles. Human plasma contains many different enzymatic and nonenzymatic antioxidant systems that serve to keep down the levels of free radicals, permitting them to perform useful biological functions without excessive damage (Halliwell et al. 1990; Valko et al. 2006).

Melatonin (N-acetyl-5-methoxytryptamine) is an endogenously-produced indol found in the pineal gland as well as in several extra pineal tissues such as retina, gastrointestinal tract and some cerebral structures (Karasek and Winczyk 2006; Jimenez-Jorge et al. 2007), which regulates many physiological functions (Konturek et al. 2007). Since 
1991, melatonin has been known as a powerful endogenic antioxidant and radical scavenger (Ianas et al. 1991). This hormone has been able to cross biological barriers, for instance the placenta and the blood-brain barrier, and can protect cell structures both directly, by reducing ROS and RNS levels, and indirectly, by increasing antioxidant enzyme concentration (Chan et al. 1996). Some of its natural features such as high lipophilicity and hydrophilicity, small size and its ability to concentrate more easily in nucleus rather than cytoplasm, help to prevent oxidative damage to DNA, enzymes or biological membranes (Karbownik et al. 2000; Simonneaux and Ribelayga 2003). Melatonin plays a direct role in mitochondrial homeostasis and reduces mitochondrial oxidative stress (Reiter et al. 1999).

Herrera et al. (2001) demonstrated that a single oral dose $(0.3 \mathrm{mg} / \mathrm{kg})$ of melatonin to chronic renal failure patients prevented oxidative stress caused by iron in anemia treatment. Similarly, melatonin $(6 \mathrm{mg} /$ day $)$ was showed to normalize the balance in the oxidant/antioxidant system in patients with postinfarction cardiosclerosis and to reduce lipid peroxidation in post-menopausal women (Wakatsuki et al. 2000; Lisitsa et al. 2005). Moreover, our previous studies showed that a fortnight administration of melatonin $(3 \mathrm{mg} /$ day) was effective in increasing the antioxidant role of plasma (Goraca et al. 2006).

Since melatonin has become available for general use better knowledge of its ability to neutralize free radicals can not only lead to better understanding of the control of physiological mechanism in health, but also can have practical implication in prevention of many pathological condition where overproduction of free radicals is observed.

The effect of a long-term administration of a non-typical pharmacological dose of several milligrams of melatonin on the antioxidant ability of human plasma has not been precisely examined. Therefore, the present study was aim at estimating the antioxidant ability of plasma from healthy volunteers after long-term oral administration of melatonin (6 mg/day for 2 weeks).

\section{Materials and Methods}

\section{Chemicals}

Thiobarbituric acid (TBA), trichloroacetic acid (TCA), sulfuric acid, butylated hydroxytoluene (BHT), sodium acetate trihydrate, TPTZ (2,4,6 tripyridyl-s-triazyine), ferric chloride hexahydrate, 1,1-diphenyl-2-picrylhydrazyl (DPPH), methanol, acetonitrile, cooper sulfate $\left(\mathrm{CuSO}_{4}\right)$, ethylenediaminetetraecetic acid (EDTA), ascorbic acid, ethidium bromide (ETBr), were purchased from Sigma Chemical Co. (St. Louis, $\mathrm{MO}, \mathrm{USA})$. Hydrogen peroxide $\left(\mathrm{H}_{2} \mathrm{O}_{2}\right)$ was purchased from $\mathrm{POCH}$ (Poland). Tablets of melatonin were purchased from
LEK-AM (Poland). Genomic high molecular weight DNA was extracted from fresh calf thymus pre-chilled with liquid nitrogen following the phenol and proteinase $\mathrm{K}$ procedure (Mozdzan et al. 2005). DNA was a kind gift from Prof. Janusz Szemraj. DNA was dissolved in water and stored $(1 \mathrm{ml})$ at $-80^{\circ} \mathrm{C}$ in Eppendorf tubes until assay.

\section{Subjects}

The study was performed on healthy volunteers (19-48 years of age) divided into two groups: the control group (without melatonin treatment; $n=10)$ and the study group $(n=10)$ treated with $6 \mathrm{mg}$ of melatonin per day for two weeks, 2 hours before bedtime. The subjects were informed of the purpose of the study. The study was approved by the local committee of Medical University of Lodz (RNN/36/02/KE) and all subjects gave their informed consent.

A necessary condition to take part in the experiment was not to receive any antioxidants (e.g. vitamin $\mathrm{C}, \mathrm{A}$ or $\mathrm{E}$ ) or medicaments with antioxidant properties, one month before blood sampling. As far as volunteers' health was concerned, $6 \mathrm{mg} /$ day has been the highest dose recommended by a manufacturer of the hormone.

\section{Blood sampling}

The volunteers were asked to attend the laboratory between 08.00-09.00 a.m. after overnight fasting, than $3 \mathrm{ml}$ of blood was drawn from the antecubital vein into vacuette tubes with EDTA as anticoagulant (for TBARS assay and DPPH reactivity assay) or heparin as anticoagulant (for antioxidant capacity assay). Blood samples were drawn as follows: before melatonin treatment, on the $7^{\text {th }}$ day of administration, on the $14^{\text {th }}$ day of administration, on the $10^{\text {th }}$ day after the end of treatment. In the control group blood was collected at the same time intervals. The blood samplings were immediately placed on ice in the dark and centrifuged within $15 \mathrm{~min}\left(3000 \times\right.$ r.p.m., $\left.4^{\circ} \mathrm{C}\right)$. Then the samples of plasma were transferred to $1.5 \mathrm{ml}$ Eppendorf tubes and stored at $-80^{\circ} \mathrm{C}$ until assay.

\section{FRAP assay}

The antioxidant plasma capacity was assayed in terms of the ferric reducing ability of plasma (FRAP) according to the original description by Benzie and Strain (1996) with some modifications. This method measures the ability of antioxidants contained in a sample to reduce ferric-tripyridyltriazine $\left(\mathrm{Fe}^{3+}-\mathrm{TPTZ}\right)$ to a ferrous form $\left(\mathrm{Fe}^{2+}-\mathrm{TPTZ}\right)$ that absorbs light at $593 \mathrm{~nm}$. In brief, the working FRAP reagent was prepared ex tempore by mixing 10 volumes of $300 \mathrm{mmol} / \mathrm{l}$ acetate buffer, $\mathrm{pH} 3.6$ with 1 vol. of $10 \mathrm{mmol} / 1 \mathrm{TPTZ}$ in $40 \mathrm{mmol} / \mathrm{l} \mathrm{HCl}$ with 1 vol. of $20 \mathrm{mmol} / 1 \mathrm{FeCl}_{3} \times 6 \mathrm{H}_{2} \mathrm{O} .50 \mu \mathrm{l}$ of plasma and $50 \mu \mathrm{l}$ of 
deionized water was added to $900 \mu \mathrm{l}$ of the FRAP reagent and the absorbance was monitored for $10 \mathrm{~min}$ ( $593 \mathrm{~nm}$; Pharmacia LKB Ultraspec III, UV/VISIBLE spectrophotometer). The FRAP value was estimated from a standard curve of ferrous sulphate and reported as $\mu \mathrm{mol} / \mathrm{l}$.

\section{$D P P H$ reactivity}

The radical DPPH is a stabile radical and is used as a tool to study the free radical scavenging action of molecules (Chrzczanowicz et al. 2008). In brief, $0.02 \mathrm{ml}$ of plasma was added to $0.02 \mathrm{ml}$ of $100 \%$ acetonitrile (for protein cutting) mixed and centrifuged for $10 \mathrm{~min}\left(10000 \times\right.$ r.p.m., $\left.17^{\circ} \mathrm{C}\right)$. Then, $0.025 \mathrm{ml}$ of supernatant was added to the reacting mixture $(0.970 \mathrm{ml}$ of $50 \%$ methanol $+0.005 \mathrm{ml} \mathrm{DPPH})$. The absorbance of the mixture was measured at $520 \mathrm{~nm}$ (Pharmacia LKB Ultraspec III, UV/VISIBLE spectrophotometer) after 3 and $30 \mathrm{~min}$. The percent inhibition in the sample was calculated based on a control with $50 \%$ DPPH in the absence of the tested molecule.

\section{Determination of TBARS}

Measurement of lipid peroxidation products was based on TBA concentration in plasma. Briefly, $1 \mathrm{ml}$ of $0.05 \mathrm{~mol} / \mathrm{l}$ $\mathrm{H}_{2} \mathrm{SO}_{4}$ and $0.5 \mathrm{ml}$ of $1.23 \mathrm{~mol} / \mathrm{l}$ TCA were added to $0.02 \mathrm{ml}$ of plasma, mixed and then centrifuged for $10 \mathrm{~min}(1500 \times \mathrm{g}$, $4^{\circ} \mathrm{C}$ ). The supernatant was discarded and the residue was mixed with $2 \mathrm{ml}$ of distilled water, $0.01 \mathrm{ml}$ of $0.01 \%$ BHT and $0.5 \mathrm{ml}$ of TBA. The obtained mixture was boiled for $30 \mathrm{~min}$. After cooling to $10^{\circ} \mathrm{C}, 2.5 \mathrm{ml}$ of butanol was added to each tube and shaken. The tubes were centrifuged for $10 \mathrm{~min}$ $\left(1500 \times g, 20^{\circ} \mathrm{C}\right)$. Fluorescence was measured at an excitation wavelength of $\lambda=515 \mathrm{~nm}$ and emission wavelength of $\lambda=546 \mathrm{~nm}$ using Perkin Elmer luminescence spectrophotometer LS 50B (Norwalk, CT, USA). The readings were converted into $\mu \mathrm{mol} / \mathrm{l}$ using the calibration curve obtained for tetrametoxypropane $(0.01-50 \mu \mathrm{mol} / \mathrm{l})$.

\section{Inhibition of DNA oxidative damage}

The hydroxyl radical $\left(\mathrm{OH}^{\bullet}\right)$ generated from $\mathrm{H}_{2} \mathrm{O}_{2}$ damages DNA structures, which facilitates oxidative modification of DNA and creation of a colored complex with ETBr. The protective effect of melatonin on DNA damage was estimated by ETBr binding assay. The plasma was defrosted and added to $2 \mathrm{ml}$ of proper mixture [ $25 \mu \mathrm{l}$ of DNA, $10 \mu \mathrm{l}$ of $\mathrm{CuSO}_{4}, 188 \mu \mathrm{l}$ of $\mathrm{H}_{2} \mathrm{O}_{2}(47 \mathrm{mmol} / \mathrm{l}), 100 \mu \mathrm{l}$ of vitamin $\mathrm{C}$ and phosphate buffer $(\mathrm{pH} 7.0)$. The samples were blended and incubated for 20 minutes $\left(25^{\circ} \mathrm{C}\right)$, before $100 \mu$ of EDTA $(10 \mathrm{mmol} / \mathrm{l})$ and $100 \mu \mathrm{l}$ of $\operatorname{ETBr}(50 \mathrm{mmol} / \mathrm{l})$ were added. The fluorescence was measured at an excitation wavelength of $\lambda=510 \mathrm{~nm}$ and emission wavelength of $\lambda=590 \mathrm{~nm}$ (Perkin Elmer luminescence spectrophotometer). The data was expressed as \% of inhibition of DNA damage performed by $\mathrm{H}_{2} \mathrm{O}_{2}-\mathrm{CuSO}_{4}$-vitamin $\mathrm{C}$ system (Mozdzan et al. 2005).

\section{Statistical analysis}

Data was expressed as mean \pm SEM. The effects were statistically analyzed by Statgraphics Centurion followed by Student's paired $t$-test. Statistical significance was considered at a level of 0.05 .

\section{Results}

\section{Total antioxidant capacity}

A constant increase of ferric reduction was observed after melatonin delivery. On the $7^{\text {th }}$ day after the oral administration of melatonin, the FRAP value increased about 1.24-fold when compared to the control. On the $14^{\text {th }}$ day of melatonin treatment and 10 day after the end of the treatment, the ferric-reducing ability remained steady at the high level of $511.53 \pm 1.15 \mathrm{mmol} / \mathrm{l}(p<0.05)$ compared to the control (Table 1).

Table 1. The effect of long-term MEL administration ( $6 \mathrm{mg} /$ day) on total antioxidant power (FRAP), level of lipid peroxidation products (TBARS), ability to protect DNA against oxidative damages and DPPH free radical scavenging

\begin{tabular}{|c|c|c|c|c|c|}
\hline & & FRAP $(\mu \mathrm{mol} / \mathrm{l})$ & TBARS $(\mu \mathrm{mol} / \mathrm{l})$ & DNA (\%) & DPPH (\%) \\
\hline \multirow{2}{*}{ control } & without MEL & $347.0 \pm 25.7$ & $11.833 \pm 0.08$ & $38.45 \pm 0.03$ & $9.8 \pm 0.7$ \\
\hline & with MEL & $378.94 \pm 0.66$ & $12.29 \pm 0.004$ & $36.98 \pm 0.18$ & $9.5 \pm 0.01$ \\
\hline \multirow{2}{*}{ treatment day 7} & without MEL & $341.5 \pm 29.7$ & $12.397 \pm 0.02$ & $39.71 \pm 0.04$ & $9.6 \pm 1.9$ \\
\hline & with MEL & $470.62 \pm 1.4^{*}$ & $2.654 \pm 0.02^{*}$ & $78.38 \pm 0.60^{\#}$ & $12.1 \pm 0.04^{*}$ \\
\hline \multirow{2}{*}{ treatment day 14} & without MEL & $363.8 \pm 43.9$ & $11.905 \pm 0.04$ & $39.21 \pm 0.01$ & $10.0 \pm 1.0$ \\
\hline & with MEL & $497.25 \pm 1.29^{*}$ & $2.581 \pm 0.01^{*}$ & $45.93 \pm 0.44^{\#}$ & $13.3 \pm 0.04^{* * *}$ \\
\hline \multirow{2}{*}{ 10-day follow up } & without MEL & $365.6 \pm 6.6$ & $11.744 \pm 0.02$ & $38.32 \pm 0.01$ & $9.3 \pm 0.8$ \\
\hline & after MEL & $511.53 \pm 1.15^{*}$ & $1.115 \pm 0.01^{* *}$ & $58.25 \pm 0.47^{\#}$ & $14 \pm 0.07^{* * *}$ \\
\hline
\end{tabular}

Values are means \pm SEM; $n=10 ;{ }^{*} p<0.05 ;{ }^{* *} p<0.02 ;{ }^{* *} p<0.01 ;{ }^{\#} p<0.001$ vs. control without MEL. 


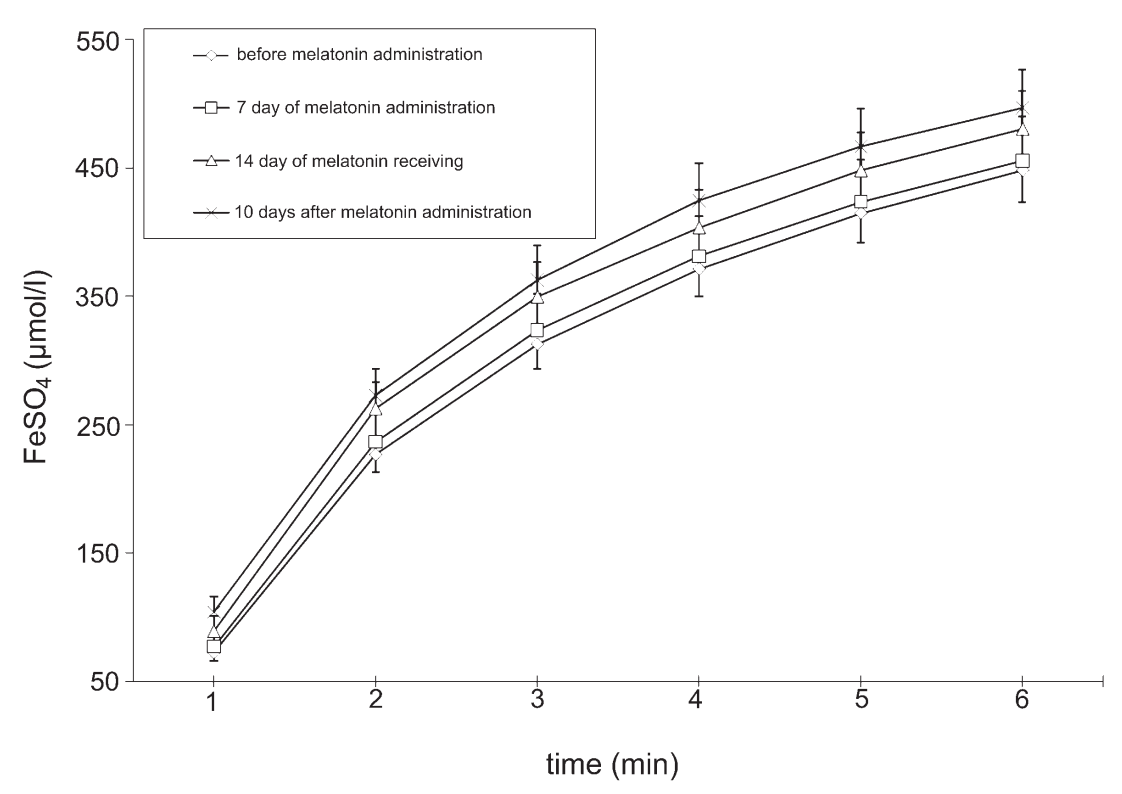

Figure 1. The effect of long-term melatonin treatment ( $6 \mathrm{mg} /$ day) on the kinetics of $\mathrm{FeSO}_{4}$ reduction of plasma. Values are means $\pm \mathrm{SEM}$; $n=10$.

The kinetics of $\mathrm{FeSO}_{4}$ reduction by plasma is shown in Fig. 1 . Plasma samples gradually increased the reduction of $\mathrm{Fe}^{3+}$ to $\mathrm{Fe}^{2+}$, which was fairly close to completion after 6 min.

\section{DPPH assay}

The plasma ability to scavenge DPPH free radical increased gradually. The highest value was recorded on the $10^{\text {th }}$ day after discontinuation of the hormone treatment $(14 \pm 0.07 \%$ vs. $9.3 \pm 0.8 \%$ in the control; $p<0.01$ ) (Table 1 ).
The kinetics of DPPH reduction by plasma is shown in Fig. 2 . The highest ability to reduce DPPH free radical was observed within $10 \mathrm{~min}$.

\section{Lipid peroxidation}

Treatment with melatonin for seven days caused about a 4.6fold decrease in lipid peroxidation level, as measured by the formation of TBARS, compared to the control $(2.654 \pm 0.02$ $\mathrm{mmol} / \mathrm{l} v s .12 .397 \pm 0.02 \mathrm{mmol} / \mathrm{l} ; p<0.05)$. On the $14^{\text {th }}$ day

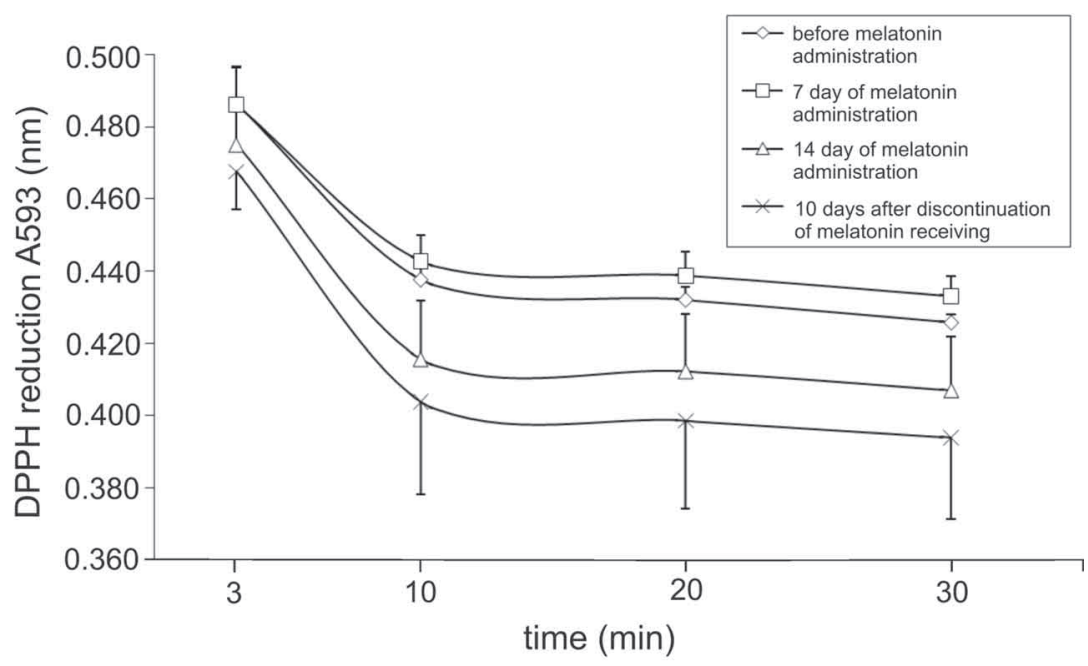

Figure 2. The effect of long-term melatonin treatment ( $6 \mathrm{mg} /$ day) on the kinetics of DPPH reduction of plasma. Values are means \pm SEM; $n=10$. 
of treatment with melatonin and 10 day follow up these values decreased to $2.581 \pm 0.01 \mathrm{mmol} / \mathrm{l}$ and $1.115 \pm 0.01$ $\mathrm{mmol} / \mathrm{l}(p<0.05, p<0.02)$, respectively (Table 1$)$.

\section{Inhibition of DNA oxidative damage}

The most potent protective effect of melatonin on DNA damage compared to the control was observed on the $7^{\text {th }}$ day of melatonin administration $(78.38 \pm 0.6 \%$ vs. $39.71 \pm$ $0.04 \% ; p<0.001)$. This effect lasted until 10 days after the treatment (Table 1).

\section{Discussion}

Our data shows that a fortnight's oral administration of melatonin significantly increases the ability of plasma to reduce $\mathrm{Fe}^{3+}$ to $\mathrm{Fe}^{2+}$. Moreover, these properties intensify during the hormone administration and persist at a high level ten days after the discontinuation of the treatment. This increase in FRAP may result from increased melatonin concentration in plasma which binds $\mathrm{Fe}^{3+}$ and converts it to a more biologically usable form of iron $\left(\mathrm{Fe}^{2+}\right)$. One undesired consequence of this conversion could be the ready provision of $\mathrm{Fe}^{2+}$, driving the Fenton reaction responsible for generation of deleterious hydroxyl radicals. Our results are in accordance with other authors who have demonstrated that oral administration of melatonin to patients with type 2 diabetes or primary essential hypertension correlates with the increased antioxidant capacity of plasma (KedzioraKornatowska et al. 2008, 2009). Similarly, infusion or oral administration of melatonin precursor L-tryptophan caused a dose-dependent increase of endogenous melatonin level in plasma (Djeridane et al. 2000; Jaworek et al. 2007). In the present study, because the volunteers were banned from intake of other antioxidants, the increase in FRAP value could be related to enhancing the synthesis of melatonin after oral supplementation of the hormone.

To evaluate and provide direct evidence of the antioxidative reactivity of melatonin, the scavenging DPPH free radical model was used. We demonstrated that plasma of volunteers who received melatonin significantly increased DPPH radical reduction. These values were significantly higher after the end of the treatment. This indicates that melatonin is able to scavenge free radicals. Similarly, Zhao el al. (2008) demonstrated that melatonin can scavenge free DPPH radical. However, Andreadou et al. (2003) showed the very weak scavenging activity of melatonin alone on $\mathrm{DPPH}$. The increased reduction of the DPPH radical by plasma may be explained by melatonin's ability to stimulate the physiological enzymatic antioxidant defense and increase of different small antioxidant molecules (Tubaro et al. 1998).
Our study indicates that the protective effect of melatonin against lipid peroxidation is visible during the first week of the hormone treatment and the TBARS level remains at a significantly low level 10 days after discontinuation of the treatment. In experimental studies in rats, it was shown that a long-term oral administration of melatonin causes a decrease in lipid peroxidation (Subramanian et al. 2007). Also, melatonin administration ( $5 \mathrm{mg} /$ day for 30 days) to elderly patients with type 2 diabetes led to an enhancement in superoxide dismutase activity and a reduction in the malondialdehyde level (Kedziora-Kornatowska et al. 2009).

Thanks to its small size, high lipophilicity and hydrophilicity, melatonin can easily penetrate the biological membrane nest between the hydrophilic heads of lipid molecules (Reiter et al. 2003). Thanks to this location and stabilization of biological membrane fluidity, the hormone is able to protect lipids from the toxic influence of ROS and RNS (Martín et al. 2000). Furthermore, melatonin inhibits $\mathrm{OH}^{\bullet}$ and $\mathrm{NOO}^{\bullet}$ formation and thus prevents polyunsaturated fatty acid oxidation (Teixeira et al. 2003; Aydogan et al. 2006).

In our study, a long-term oral administration of melatonin strongly prevented DNA damage by scavenging $\mathrm{OH}^{\bullet}$ generated from $\mathrm{H}_{2} \mathrm{O}_{2}$. Hydrogen peroxide is an immediate precursor of $\mathrm{OH}^{\circ}$, a highly damaging compound, which causes mitochondrial DNA deletion and apoptosis (Jou et al. 2007; Kimball et al. 2008). Melatonin, however, has been shown to protect cells from oxidative stress by stimulation of DNA repair (Jou et al. 2007; Sliwinski et al. 2007) and by scavenging $\mathrm{OH}^{\bullet}$ as well as $\mathrm{H}_{2} \mathrm{O}_{2}$ (Tan et al. 2000). Melatonin also increases the level of antioxidant enzymes $\left(\mathrm{Mn}^{2+}, \mathrm{Cu}^{2+}\right.$ dependent superoxide dismutase, catalase, glutathione peroxidase, glutathione reductase) (Hardeland et al. 2005; Muñoz-Casares et al. 2006) which metabolize hydrogen peroxide to oxygen and water. By removing $\mathrm{H}_{2} \mathrm{O}_{2}$ enzymatically, the formation of the highly reactive $\mathrm{OH}^{*}$ would be reduced and DNA would be less damaged.

In conclusion, the results of the present study indicate that a long-term oral administration of melatonin significantly increases plasma antioxidant power and prevents oxidative damages to DNA. This protective effect of melatonin is maintained at least for 10 days after the end of the hormone treatment.

Acknowledgement. The study was supported by a grant 503-0079-3 from the Medical University of Lodz.

\section{References}

Andreadou I., Tsantili-Kakoulidou A., Spyropoulou E., Siatra T. (2003): Reactions of indole derivatives with cardioprotec- 
tive activity with reactive oxygen species. Comparison with melatonin. Chem. Pharm. Bull. (Tokyo) 51, 1128 1131; doi:10.1248/cpb.51.1128

Aydogan S., Yerer M. B., Goktas A. (2006): Melatonin and nitric oxide. J. Endocrinol. Invest. 29, 281-287

Benzie I. F., Strain J. J. (1996): The ferric reducing ability of plasma (FRAP) as a measure of "antioxidant power": the FRAP assay. Anal. Biochem. 239, 70-76; doi:10.1006/ abio.1996.0292

Chan T. Y., Tang P. L. (1996): Characterization of the antioxidant effects of melatonin and related indoleamines in vitro. J. Pineal. Res. 20, 187-191; doi:10.1111/j.1600-079X.1996. tb00257.x

Chrzczanowicz J., Gawron A., Zwolinska A., de Graft-Johnson J., Krajewski W., Krol M., Markowski J., Kostka T., Nowak D. (2008): Simple method for determining human serum 2,2-diphenyl-1-picryl-hydrazyl (DPPH) radical scavenging activity - possible application in clinical studies on dietary antioxidants. Clin. Chem. Lab. Med. 46, 342-349; doi:10.1515/CCLM.2008.062

Djeridane Y., Pitrosky B., Viven-Roels B., Simonneaux V., Kirsch R., Pévet P. (2000): Long-term daily melatonin infusion induces a large increase in $\mathrm{N}$-acetyltransferase activity, hydroxyindole-O-methyltransferase activity, and melatonin content in the Harderian gland and eye of pinealectomized male Siberian hamsters (Phodopus syngorus). J. Pineal. Res. 29, 65-73; doi:10.1034/j.1600079X.2000.290201.x

Goraca A., Cieśla W. (2006): The role of melatonin in lipid peroxidation in healthy subjects. Pol. Merkur. Lekarski 21, 59-61 (in Polish)

Halliwell B., Gutteridge J. M. (1990): The antioxidants of human extracellular fluids. Arch. Biochem. Biophys. 280, 1-8; doi:10.1016/0003-9861(90)90510-6

Hardeland R., Pandi-Perumal S. R. (2005): Melatonin, a potent agent in antioxidative defense: Actions as a natural food constituent, gastrointestinal factor, drug and prodrug. Nutr. Metab. 2, 22; doi:10.1186/1743-7075-2-22

Herrera J., Nava M., Romero F., Rodríguez-Iturbe B. (2001): Melatonin prevents oxidative stress resulting from iron and erythropoietin administration. Am. J. Kidney Dis. 37, 750-757; doi:10.1016/S0272-6386(01)80124-4

Ianas O., Olinescu R., Badescu I. (1991): Melatonin involvement in oxidative stress. Endocrinologie 29, 147-153

Jaworek J., Nawrot-Porabka K., Leja-Szpak A., Bonior J., Szklarczyk J., Kot M., Konturek S. J., Pawlik W. W. (2007): Melatonin as modulator of pancreatic enzyme secretion and pancreatoprotector. J. Physiol. Pharmacol. 58, 65-80

Jimenez-Jorge S., Guerrero J. M., Jimenez-Caliani A. J., Naranjo M. C., Lardone P. J., Carrillo-Vico A., Osuna C., Molinero P. (2007): Evidence for melatonin synthesis in the rat brain during development. J. Pineal. Res. 42, 240-246; doi:10.1111/j.1600-079X.2006.00411.x

Jou M. J., Peng T. I., Yu P. Z., Jou S. B., Reiter R. J., Chen J. Y., Wu H. Y., Chen C. C., Hsu L. F. (2007): Melatonin protects against common deletion of mitochondrial DNA-augmented mitochondrial oxidative stress and apoptosis. J. Pineal. Res. 43, 389-403; doi:10.1111/ j.1600-079X.2007.00490.x

Karasek M., Winczyk K. (2006): Melatonin in humans. J. Physiol. Pharmcol. 57, 19-39

Karbownik M., Reiter R. J., Qi W., Garcia J. J., Tan D. X., Manchester L. C., Vijayalaxmi (2000): Protective effects of melatonin against oxidation of guanine bases in DNA and decreased microsomal membrane fluidity in rat liver induced by whole body ionizing radiation. Mol. Cell. Biochem. 211, 137-144; doi:10.1023/A:1007148530845

Kawanishi S., Murata M. (2006): Mechanism of DNA damage induced by bromate differs from general types of oxidative stress. Toxicology 221, 172-178; doi:10.1016/ j.tox.2006.01.002

Kedziora-Kornatowska K., Szewczyk-Golec K., Czuczejko J., Pawluk H., van Marke de Lumen K., Kozakiewicz M., Bartosz G., Kedziora J. (2008): Antioxidative effects of melatonin administration in elderly primary essential hypertension patients. J. Pineal Res. 45, 312-317; doi:10.1111/j.1600079X.2008.00592.x

Kedziora-Kornatowska K., Szewczyk-Golec K., Kozakiewicz M., Pawluk H., Czuczejko J., Kornatowski T., Bartosz G., Kedziora J. (2009): Melatonin improves oxidative stress parameters measured in the blood of elderly type 2 diabetic patients. J. Pineal Res. 46, 333-337; doi:10.1111/ j.1600-079X.2009.00666.x

Kimball S. R., Abbas A., Jefferson L. S. (2008): Melatonin represses oxidative stress-induced activation of the MAP kinase and mTOR signaling pathways in H4IIE hepatoma cells through inhibition of Ras. J. Pineal Res. 44, 379-386; doi:10.1111/j.1600-079X.2007.00539.x

Konturek S. J., Konturek P. C., Brzozowska I., Pawlik M., Sliwowski Z., Cześnikiewicz-Guzik M., Kwiecień S., Brzozowski T., Bubenik G. A., Pawlik W. W. (2007): Localization and biological activities of melatonin in intact and diseased gastrointestinal tract (GIT). J. Physiol. Pharmacol. 58, 381-405

Lisitsa G. V., Zaslavskaia R. M., Kalinina E. V. (2005): Effectiveness of metabolic preparations in complex treatment of elderly patients with postinfarction cardiosclerosis and circulatory insufficiency. Klin. Med. (Mosk.) 83, 54-57 (in Russian)

Martín M., Marcías M., Escames G., León J., Acuña-Castroviejo D. (2000): Melatonin but not vitamins $C$ and $E$ maintain glutathione homeostasis in t-butyl hydroperoxideinduced mitochondrial oxidative stress. FASEB J. 14, $1677-1679$

Mozdzan M., Szemraj J., Rysz J., Nowak D. (2005): Antioxidant properties of carnosine re-evaluated with oxidizing system involving iron and copper ions. Basic. Clin. Pharmacol. Toxicol. 96, 352-360; doi:10.1111/j.17427843.2005.pto_03.x

Muñoz-Casares F. C., Padillo F. J., Briceño J., Collado J. A., MuñozCastaneda J. R., Ortega R., Cruz A., Túnez I., Montilla P., Pera C., Muntané J. (2006): Melatonin reduces apoptosis and necrosis induced by ischemia/reperfusion injury of the pancreas. J. Pineal. Res. 40, 195-203; doi:10.1111/ j.1600-079X.2005.00291.x 
Reiter R. J., Tan D. X., Cabrera J., D’Arpa D., Sainz R. M., Mayo J. C., Ramos S. (1999): The oxidant/antioxidant network: role of melatonin. Biol. Signals Recept. 8, 56-63; doi:10.1159/000014569

Reiter R. J., Tan D. X., Manchester L. C., Lopez-Burillo S., Sainz R. M., Mayo J. C. (2003): Melatonin: detoxification of oxygen and nitrogen-based toxic reactants. Adv. Exp. Med. Biol. 527, 539-548

Simonneaux V., Ribelayga C. (2003): Generation of the melatonin endocrine message in mammals: a review of the complex regulation of melatonin synthesis by norepinephrine, peptides and other pineal transmitters. Pharmacol. Rev. 55, 325-395; doi:10.1124/pr.55.2.2

Sliwinski T., Rozej W., Morawiec-Bajda A., Morawiec Z., Reiter R., Blasiak J. (2007): Protective action of melatonin against oxidative DNA damage: chemical inactivation versus base-excision repair. Mutat. Res. 634, 220-227

Subramanian P., Mirunalini S., Pandi-Perumal S. R., Trakht I., Cardinali D. P. (2007): Melatonin treatment improves the antioxidant status and decreases lipid content in brain and liver of rats. Eur. J. Pharmacol. 571, 116-119; doi:10.1016/j.ejphar.2007.06.011

Tan D. X., Manchester L. C., Reiter R. J., Plummer B. F., Limson J., Weintraub S. T., Qi W. (2000): Melatonin directly scavenges hydrogen peroxide: a potentially new metabolic pathway of melatonin biotransformation. Free Radic. Biol. Med. 29, 1177-1185; doi:10.1016/S0891-5849(00)00435-4
Teixeira A., Morfim M. P., de Cordova C. A., Charao C. C., de Lima V. R., Creczynski-Pasa T. B. (2003): Melatonin protects against pro-oxidant enzymes and reduces lipid peroxidation in distinct membranes induced by the hydroxyl and ascorbyl radicals and by peroxynitrite. J. Pineal Res. 35, 262-268; doi:10.1034/j.1600079X.2003.00085.X

Tubaro F., Ghiselli A., Rapuzzi P., Maiorino M., Ursini F. (1998): Analysis of plasma antioxidant capacity by competition kinetics. Free Radic. Biol. Med. 24, 1228-1234; doi:10.1016/S0891-5849(97)00436-X

Valko M., Rhodes C. J., Moncol J., Izakovic M., Mazur M. (2006): Free radicals, metals and antioxidants in oxidative stress-induced cancer. Chem. Biol. Interact. 160, 1-40; doi:10.1016/j.cbi.2005.12.009

Wakatsuki A., Okatani Y., Ikenoue N., Izumiya C., Kaneda C. (2000): Melatonin inhibits oxidative modification of low-density lipoprotein particles in normolipidemic postmenopausal women. J. Pineal Res. 28, 136-142

Zhao F., Liu Z. Q., Wu D. (2008): Antioxidative effect of melatonin on DNA and erythrocytes against free-radical-induced oxidation. Chem. Phys. Lipids 151, 77-84; doi:10.1016/ j.chemphyslip.2007.10.002

Received: June 22, 2009

Final version accepted: January 8, 2010 